\title{
Numerical Study of Stainless Steel Pitting Process Based on the Lattice Boltzmann Method
}

\author{
Jing Cui, Fan Yang, Ting- Hao Yang, Guang-Feng Yang* \\ Civil Aviation University of China Airport College, Tianjin 300300,China \\ *E-mail: cuijingygfeng@ sina.com \& gfyang@ cauc.edu.cn
}

doi: $10.20964 / 2019.02 .47$

Received: 12 September 2018 / Accepted: 27 Nobember 2018 / Published: 5 January 2019

\begin{abstract}
The application of computers to numerical calculations has become an important means of studying corrosion problems, and in this work, the lattice Boltzmann method (LBM) was used to numerically simulate the pitting corrosion of stainless steel. The multi-phase multi-component model, electrochemical reaction model and phase change model were applied to construct a new lattice Boltzmann corrosion model based on the Lattice Boltzmann method and corrosion kinetics behaviour. Moreover, the passivation probability was employed for modifying the chemical reaction rate, and the Volume of Pixel method was adopted for treating the migration of the solid boundary. A realistic liquid corrosion environment was constructed using the lattice Boltzmann method to simulate the concentration profiles of different components. The pitting corrosion characteristics of stainless steel were investigated numerically using this proposed model. Moreover, the unsteady topological structures of the corrosion pit and the instantaneous concentration distribution of the various components were obtained. In addition, specific chemical reactions and electrochemical reactions were introduced into the corrosion model to ensure the conservation of mass. The reaction mechanism of stainless steel pitting corrosion was clearly explained by using this model.
\end{abstract}

Keywords: Lattice Boltzmann method, Pitting on stainless steel, Electrochemical reactions, Volume of Pixel, Passivation probability

\section{$\underline{\text { FULL TEXT }}$}

(C) 2019 The Authors. Published by ESG (www.electrochemsci.org). This article is an open access article distributed under the terms and conditions of the Creative Commons Attribution license (http://creativecommons.org/licenses/by/4.0/). 